\title{
ACERCA DO JOVEM NO MERCADO DE TRABALHO: uma breve retrospectiva das propostas educativas no ensino profissionalizante no Brasil
}

\author{
Cláudia Barbosa Lôbo' \\ Marco Antônio de Oliveira Gomes²
}

\section{RESUMO}

Neste trabalho analisamos os aspectos históricos, políticos e ideológicos das propostas do ensino profissionalizante no Brasil ao longo do período republicano. Assim, nosso objetivo pautou-se pela análise das justificativas e argumentos que consideram a existência de uma formação deficiente como responsável pela geração da exclusão, miséria e a ausência de mão de obra qualificada para o atendimento das necessidades econômicas do país. Como ponto de partida metodológico, levamos em consideração que a educação, como qualquer outra dimensão das relações sociais, vincula-se intrinsecamente com a estrutura de classes instituídas historicamente. Assim, a questão da educacional não pode ser pensada como se fosse um sistema ou subsistema à parte na vida social. De forma sintética, é possível indicar que o ensino profissionalizante está inserido num modelo dual de educação, que não alterou, nem poderia, a condição de classe dos filhos dos trabalhadores. Por fim, buscamos aporte teórico em autores como Frigotto (2010), Saviani (2011) e Romanelli (1978), considerando as categorias de análise do materialismo histórico e dialético.

Palavras-chave: Educação Profissionalizante. Mercado de Trabalho. Educação Brasileira.

\section{ABOUT YOUNG PEOPLE IN THE JOB MARKET: a brief retrospective of educational proposals in professional education in Brazil}

\begin{abstract}
1 Mestre (2015) em Educação pelo Programa de Pós-Graduação Stricto Sensu em Educação pela Universidade Federal de Rondônia (UNIR). Professora do Núcleo de Educação da Faculdade Metropolitana Porto velho - RO. Orcid iD: http://orcid.org/0000-0002-2397-5615. E-mail: claudiapvh@hotmail.com

${ }^{2}$ Doutorado (2008) em História e Filosofia da Educação pela Universidade Estadual de Campinas (Unicamp). Professor adjunto da Universidade Estadual de Maringá, lotado no Departamento de Fundamentos da Educação. Orcid iD: http://orcid.org/0000-0003-08984932. E-mail: marcooliveiragomes@yahoo.com.br
\end{abstract}


In this work, we analyze the historical, political and ideological aspects of the professional education proposals in Brazil throughout the republican period. Therefor, our objective was based in the analysis of justifications and arguments that consider the existence of a deficient formation as the responsible for the generation of the exclusion, poverty and the skilled labor absence to service the country's economics needs. As a methodological basis, we consider that education, like any other society relations dimension, it's intrinsically binded up with the historically instituted class structure. Therefore, the question about the education can't be thinked like a system or subsystem apart the social life. So, it's possible indicate, synthetically, that the professional education is inserted in a dual model of education that did not, and could not, change the worker's children class condition. At the end, we seek theoretical contribution in authors like Frigotto (2010), Saviani (2011) e Romanelli (1978), considering the analysis category of historical and dialectical materialism.

Keywords: Professional Education. Job market. Brazilian Education.

\section{ACERCA DEL JOVEN EN EL MERCADO DE TRABAJO: una breve retrospectiva de las propuestas educativas en la enseñanza profesionalizante en Brasil}

\section{RESUMEN}

En este trabajo analizamos los aspectos históricos, políticos e ideológicos de las propuestas de enseñanza profesionalizante en Brasil a lo largo del período republicano. De esta forma, nuestro objetivo estaba determinado por el análisis de las justificaciones y argumentos que consideran la existencia de una formación deficiente como responsable por la generación de exclusión, miseria y la ausencia de mano de obra cualificada para la atención de las necesidades económicas del país. Como punto de partida metodológico, consideramos que, como cualquier otra dimensión de las relaciones sociales, la educación se vincula intrínsecamente con la estructura de clases instituidas históricamente. Así, la cuestión educacional no puede ser pensada como si fuera un sistema o subsistema aparte de la vida social. De forma sintética, es posible indicar que la enseñanza profesionalizante está inserta en un modelo dual de educación que no alteró, ni podría, la condición de clase de los hijos de los trabajadores. Por último, buscamos el aporte teórico en autores como Frigotto (2010), Saviani (2011) y Romanelli (1978), considerando las categorías de análisis del materialismo histórico y dialéctico.

Palabras-clave: Educación Profesional. Mercado de trabajo. Educación Brasileña.

\section{INTRODUÇÃO}

Desde o processo de consolidação do capitalismo, a educação foi apresentada em diferentes momentos históricos como solução para os problemas sociais. Guardadas as especificidades do caso brasileiro, é possível afirmar que essa tendência se repetiu em nosso país. Ao longo do 
século XX, é possível identificar inúmeras iniciativas do Estado objetivando, por meio da educação, formar a mão de obra nacional e minimizar, ao mesmo tempo, as lutas de classes.

Assim, no presente trabalho, serão abordadas questões acerca do tema referente ao jovem no mercado de trabalho e as propostas de ensino profissionalizante no Brasil, numa perspectiva histórica, buscando apresentar as políticas públicas no período republicano, de acordo com os contextos político, econômico e social de cada período.

Em uma breve síntese, é possível afirmar que as lutas populares ao longo da República e os interesses dos grupos dominantes em reduzir o ímpeto das lutas de classes contribuíram para a construção de políticas governamentais objetivando a qualificação profissional. Assim, buscamos compreender as origens de suas propostas no processo contraditório do modo de produção capitalista e seus desdobramentos para a educação.

Isto posto à luz do materialismo histórico e dialético, realizamos uma revisão bibliográfica, além do levantamento de iniciativas do Estado para a educação profissional. O referencial se fez por meio de uma opção teórica alicerçada em autores como Frigotto (2010), Saviani (2011) e Romanelli (1978).

\section{A ilusão liberal: a educação profissionalizante e a defesa da harmonia entre capital e trabalho}

As questões acerca da juventude adquiriram grande relevância diante dos problemas sociais gerados pelo desemprego e pela violência que atingem essa parcela da população, especialmente os filhos da classe trabalhadora. Diante disso, propõe-se refletir este ensaio sobre as políticas de educação profissional ao longo da República no Brasil.

Antes mesmo do período republicano no Brasil, especificamente no início do período imperial (1822-1889), com a Constituição outorgada em 1824, verifica-se a proposta de se contemplar a questão da educação pública alicerçada nos princípios liberais da Revolução Francesa, 
adaptando-os aos interesses das classes proprietárias de terras e escravos. No entanto, só de forma superficial, o tema foi abordado na Carta de 1824, que traçou as diretrizes que vieram a delimitar as formas que essa modalidade de ensino tomou no futuro.

O ensino profissional praticamente não registrou progresso, o que era coerente com o padrão da sociedade construída desde o período colonial (1500-1822), que preservou a separação tida entre o trabalho destinado para os negros escravos ou homens livres pobres e a instrução para a elite.

\begin{abstract}
As iniciativas com a educação elementar muitas vezes eram apenas as proclamadas nos decretos, como as do Projeto Januário da Cunha Barbosa, de 15 de outubro de 1827, que instituía as "Escolas de Primeiras Letras", como resposta à Constituição de 1824 que garantia a instrução primária a todo cidadão do Império. Mas como não instituía também as condições necessárias para a efetivação do decreto, o projeto acabou por não se expandir de fato. A instrução popular não era necessária e a ela não era dada muita ênfase, apesar de proclamada do decreto que a instituía. Por não ter utilidade social prática para modelo econômico agro-exportador que até então era vigente (CARVALHO, 2008, p.64).
\end{abstract}

Acrescente-se que, para além da falta de interesse dos grandes proprietários e do Estado, a falta de recursos funcionou como um poderoso obstáculo ao processo de expansão da educação escolar. Assim, a legislação que se segue não alterou significativamente o panorama da educação escolar no Brasil.

A respeito da educação profissional no país, ao longo do século XIX, verificam-se apenas decisões fragmentadas e pontuais destinadas, especialmente, a "amparar os órfãos e os demais desvalidos da sorte", assumindo notoriamente um caráter assistencialista, conforme relatório da Educação Profissional Legislação Básica:

A partir da década de 40 do século XIX foram construídas dez
Casas de Educando e Artífices em capitais de província, sendo
a primeira delas em Belém do Pará, para atender
prioritariamente aos menores abandonados, objetivando "a
diminuição da criminalidade e da vagabundagem".
Posteriormente, Decreto Imperial de 1854 criava 
estabelecimentos especiais para menores abandonados, os chamados Asilos da Infância dos Meninos Desvalidos, onde os mesmos aprendiam as primeiras letras e eram, a seguir, encaminhados às oficinas públicas e particulares, mediante contratos fiscalizados pelo Juizado de Órfãos. Na segunda metade do século passado foram criadas, ainda, várias sociedades civis destinadas a "amparar crianças órfãs e abandonadas", oferecendo-lhes instrução teórica e prática, e iniciando-as no ensino industrial. As mais importantes delas foram os Liceus de Artes e Ofícios, entre os quais os do Rio de Janeiro (1858), Salvador (1872), Recife (1880), São Paulo (1882), Maceió (1884) e Ouro Preto (1886) (BRASIL, 1999, p.9).

No entanto, o processo de expansão da lavoura cafeeira, a aceleração da urbanização, as lutas travadas em torno da abolição da escravidão e o crescimento da produção, criaram um ambiente propício para as novas ideias. Diante das novas circunstâncias, verifica-se a emergência de um discurso de defesa do ensino técnico/profissional, que se vinculava à preocupação dos segmentos dominantes em manter a ordem.

[...] Nasce dessa preocupação a Escola dos Desvalidos, em 1874, e algumas escolas agrícolas, origem da escola profissional masculina. Nesse sentido, associou-se o ensino profissional à preservação da ordem social (afastamento dos desvalidos da marginalidade) e à assistência (GALLINDO, in BATISTA; MEIRE, 2013, p.47).

Não por acaso, o período é marcado por transformações na ordem econômica que geraram novos interesses nas disputas políticas. Além da abolição, acrescente-se a entrada de imigrantes que vinha ocorrendo de forma sistemática desde o final da primeira metade do século XIX e o crescimento do mercado interno.

No rol das transformações verifica-se que:

A população do Brasil, na primeira década do século XIX, era de cerca de três milhões de habitantes, sendo que, destes, 1,6 milhões eram escravos. Havia ainda cerca de 400 mil negros e mulatos libertos e um milhão de brancos. Essa população vai alcançar um total de dez milhões em 1872, chegando a 17,3 milhões na virada do século XX. No total, os negros e mulatos, ditos "livres e libertos", constituirão o subgrupo populacional que mais crescerá no decorrer do século XIX. Nas áreas rurais, exercerão atividades ligadas principalmente à 
agricultura/pecuária de subsistência. Nas cidades e vilas, desenvolver-se-ão nos ramos de serviços em geral, na produção artesanal e ainda em atividades manufatureiras. Muitos, entretanto, não encontravam outras atividades além do trabalho ocasional em atividades de pequenos serviços, quando não se encontravam em situação de privação de trabalho (THEODORO, 2008, p.21).

Nesse cenário, observa-se um processo de industrialização incipiente no Brasil que pode ser explicado pelo investimento dos grandes latifundiários, associado ao capital britânico, além das condições de infraestrutura gerada pela expansão da produção cafeeira com a mão de obra assalariada.

A Proclamação da República, em 1889, não rompeu com as estruturas herdadas do Império. A economia continuava basicamente agrárioexportadora, as terras permaneciam concentradas nas mãos de poucos, e, aqueles que não possuíam nada, além de sua força de trabalho, continuavam com direitos limitados e não respeitados. Diante das condições precárias de existência, muitos se rebelaram no alvorecer da República. No entanto, o Estado oligárquico utilizava da repressão para conter os trabalhadores. Exemplo típico dessa situação é a frase atribuída a Washington Luiz: "A questão social é um 'caso de polícia'".

No cenário de domínio das oligarquias agrário-exportadoras, o ensino profissional ainda era marcado pelo assistencialismo e por um discurso de "regeneração social". As escolas de aprendizes e artífices eram destinadas "aos pobres e humildes", como pode ser verificado por meio do Decreto $\mathrm{n}^{\circ}$ 7.566, de 23 de setembro de 1909, o qual cria Escolas de Aprendizes artífices para o ensino profissionalizante, primário e gratuito:

O Presidente da Republica dos Estados Unidos do Brazil, em execução da lei n. 1.606, de 29 de dezembro de 1906: Considerando: que o augmento constante da população das cidades exige que se facilite às classes proletárias os meios de vencer as dificuldades sempre crescentes da luta pela existência: que para isso se torna necessário, não só habilitar os filhos dos desfavorecidos da fortuna com 0 indispensável preparo technico e intelectual, como faze-los adquirir habitos de trabalho profícuo, que os afastara da ociosidade ignorante, escola do vicio e do crime; que é um dos primeiros deveres do Governo da Republica formar cidadãos uteis à Nação. 
Decreta: Art. $2^{\circ}$. Nas Escolas de Aprendizes Artifices, custeadas pela União, se procurará formar operarios e contra-mestres, ministrando-se o ensino pratico e os conhecimentos technicos necessarios aos menores que pretendem aprender um officio, havendo para isso até o numero de cinco officinas de trabalho manual ou mecanico que forem mais convenientes e necessarias no Estado em que funccionar a escola, consultadas, quanto possivel, as especialidades das industrias locaes. [...] Art. $6^{\circ}$. Serão admitidos os individuos que 0 requererem dentro do prazo marcado para a matrícula e que possuirem os seguintes requisitos, preferidos os desfavorecidos da fortuna: a) idade de 10 annos no minimo e de 13 annos no maximo; b) não soffrer o candidato molestiainfectocontagiosa, nem ter defeitos que 0 impossibilitem para 0 aprendizado do officio. $\S 1^{\circ}$. A prova desses requisitos se fará por meio de certidão ou attestado passador por autoridade competente. $\S 2^{\circ}$. A prova de ser o condidatodestituido de recursos será feita por attestação de pessoas idoneas, a juizo do director, que poderá dispensal-a quando conhecer pessoalmente as condições de requerente à matricula.

Como se vê, estava presente na pena do legislador, a perspectiva liberal de remediar as condições materiais dos filhos da classe trabalhadora por meio da educação. Dito de outra forma, a educação profissional objetivava criar hábitos de trabalho que afastariam os jovens dos vícios e do crime em uma sociedade que negava estruturalmente o trabalho a todos. Desconsideravam-se, na prática, as condições materiais que geravam a massa de trabalhadores pobres e ociosos.

Como decorrência da Lei 1.606/1909, foram instaladas, a partir de 1910, 19 (dezenove) Escolas de Aprendizes Artífices distribuídas em várias unidades da Federação. Eram instituições semelhantes aos Liceus de Artes e Ofícios, voltadas basicamente ao ensino industrial, custeadas pelo Estado.

Entretanto, as Escolas de Aprendizes Artífices contavam com investimento precário, pois os ofícios eram mais artesanais do que industriais.

Assim, os resultados não foram convergentes com aqueles proclamados pela Lei, o que levou o Ministério da Agricultura e Indústria a nomear uma comissão de especialistas, para reformular 0 ensino profissionalizante, chefiada pelo engenheiro João Lüderitz.

Segundo Rodrigues (2002, p.13): 
A Comissão Lüderitz propôs mudanças na estrutura das escolas e nos currículos, introduziu o conceito de "industrialização das escolas" 17; traduziu e produziu livros-texto sobre literatura técnica, que até então não existiam em língua portuguesa no Brasil. Tais propostas foram reunidas no Projeto de Regulamentação do Ensino Profissional Técnico e apresentado ao Governo Central em 1923. De fato, o Projeto nunca foi aprovado, muito embora algumas de suas proposições tenham sido incorporadas paulatinamente.

Para Gomes (2013), a compreensão das preocupações com a reformulação do ensino profissionalizante vincula-se à expansão do desenvolvimento industrial e comercial que se verificava efetivamente após 1914, período da Primeira Guerra Mundial (1914-1918), que estimulou indiretamente o crescimento do polo industrial.

No cenário das transformações ocorridas nos anos 1920, período marcado pelo questionamento da ordem oligárquica, pela ascensão das camadas médias, pela Semana de Arte Moderna, pelo Movimento Tenentista, entre outros, o tema da educação ocupou a pauta de diferentes intelectuais.

Dado o momento, marcado pelo otimismo pedagógico e pelo entusiasmo pela educação, a educação escolar era apresentada como instrumento de desenvolvimento nacional.

No entanto, o processo de expansão escolar não contemplou a todos. A maioria da classe trabalhadora continuava excluída da escola.

Somente neste período de transformação econômica, no modo de produção, cresce a demanda social por educação. O Estado, então, expande o quadro escolar, porém, prescreve para a escola um tipo de formação limitado: o da instituição para o trabalho. Para Romanelli (1985), o conteúdo dessa expansão, apesar de grande, não foi suficiente para atingir a população, logo, a marginalização continuou sendo um fato presente na educação. Para a autora, os aspectos dessa marginalização eram os da oferta insuficiente, do baixo rendimento interno do sistema escolar (pouca ascensão possível na carreira escolar e da discriminação social que prevalecia, marcada pelo dualismo escolar (GOMES, 2013, p.65). 
Como decorrência das transformações do período, verifica-se o surgimento da Associação Brasileira de Educação (ABE), em 1924, reunindo educadores que enxergavam a educação como a responsável por inserir as pessoas na ordem social.

Com a Revolução de 1930, muitos educadores que integraram o movimento de renovação passaram a ocupar espaços nas diferentes esferas do poder que se constituíam com a ascensão de Getúlio Vargas. Tratava-se de um período marcado pela criação do Ministério da Educação e Saúde Pública, transformando-a em uma questão nacional.

O primeiro Ministro da Pasta, Francisco Campos, promoveu a reforma que levaria seu nome, em 1931, estabelecendo, em âmbito nacional, a modernização do ensino secundário.

Em linhas gerais é possível afirmar que organizou o ensino secundário por meio de diferentes estratégias escolares, que podem ser assim elencadas: seriação do currículo; frequência obrigatória dos alunos; imposição de um detalhado e regular sistema de avaliação discente e a reestruturação do sistema de inspeção federal. No entanto, a expansão escolar não atendeu a demanda dos filhos das classes trabalhadoras.

A respeito da Reforma "Francisco Campos", Romanelli (1978, p.141-2) apresenta a seguinte contribuição:

a) A reforma deixou completamente marginalizados os ensinos primário e normal e os vários ramos do ensino médio profissionalizante, salvo o comércio. Praticamente, a reforma tratou de organizar preferentemente o sistema educacional das elites. A obrigatoriedade de se prestarem exames para admissão ao ensino médio, nos quais se exigiam conhecimentos jamais fornecidos pela escola primária, importava em conhecer a nulidade desta. b) A reforma tampouco tratou de estabelecer articulação entre os vários ramos do ensino médio. Pelo contrário, ao considerar os ensinos secundários e comercial, tratou, antes de criar dois sistemas rígidos e fechados, sem qualquer abertura ou possibilidade de transferência de um para o outro. Por não ter cuidado, ao mesmo do ensino industrial, numa hora em que o país despertava para o problema da industrialização, deu a reforma, na verdade, um passo atrás, perdendo a oportunidade que o contexto oferecia de criar um sistema e ensaiava seus primeiros passos na vida política nacional. 
Perdeu também a oportunidade social de educação nascente.

A Reforma "Francisco Campos" nada mais foi que expansão da escola em limites estreitos, uma reforma baseada na manutenção da educação com privilégio de classe.

Assim como a rigidez da Reforma Capanema do ensino secundário, as ideologias nela implícitas, dão bem a medida da atuação das correntes conservadoras e da burguesia antidemocrática junto ao Poder Executivo (ROMANELLI, 1978), portanto, ambas não trouxeram nenhum tipo de ruptura com o caráter dual da educação, mas reforçou-o, reafirmando a atuação das correntes conservadoras junto ao Poder Executivo.

Cabe enfatizar que as reformas do período devem ser compreendidas dentro do cenário de uma política de Estado, marcada pela substituição de importações. Buscava-se fortalecer a chamada "indústria nacional" por meio de uma política protecionista.

Ao mesmo tempo, o Estado criou um sistema paralelo de ensino, estabelecido em convênio assinado com a Confederação Nacional das Indústrias, por meio do Decreto Lei $n^{\circ} 4.048$, de 1942, que originou o Serviço Nacional da Aprendizagem Industrial (SENAI). Em 1946, pelo Decreto Lei $n^{\circ}$ 8.621, foi criado o Serviço Nacional de Aprendizagem Comercial (SENAC). As duas instituições foram criadas para atender a demanda de qualificação dos trabalhadores para todos os níveis de profissionalização.

Segundo Gomes (2013, p.67-8):

Nas primeiras décadas do século XX, O Brasil apresentava um quadro urbano diferente e já era claro o processo de industrialização gerado pelo desenvolvimento do sistema capitalista no país. Devido à oferta de trabalho, houve o aumento de migrantes da zona rural para as cidades. Esse processo de expansão da indústria e do comércio foi mais efetivo após a Segunda Guerra Mundial. Como a maioria do contingente de trabalhadores não tinham formação específica, considerando que o sistema educacional não os conseguia atender em larga escala, o governo recorreu à institucionalização de agências profissionalizantes paralelas ao sistema oficial a fim de preparar a mão de obra para esses serviços. 
É importante ressaltar que o convênio entre o Estado e a Confederação Nacional das Indústrias e do Comércio é uma forma de privatização da responsabilidade da educação profissional, pois trata-se de uma instituição criada pelo governo, mas mantida pelo comércio e indústria.

Segundo Romanelli, aí está o significado da criação e da manutenção do sistema paralelo do ensino, ao lado de um sistema oficial.

Romanelli (1978, p.114) faz a seguinte colocação:

\begin{abstract}
Outro fato está a merecer nossa atenção. Se a preparação para o trabalho não é feita na escola, onde tem sido feita até agora? A questão envolve vários aspectos. Em princípio, devido considerar-se presença maciça, em nossa indústria e no setor terciário, de imensa massa de empregados nãoqualificados. Esse fato tem dado até uma certa tônica à nossa expansão econômica. Não cabe analisá-lo aqui agora. Em seguida, deve destacar-se o treinamento feito nos próprios locais de trabalho, de que falamos acima. Por último, deve mencionar-se a contribuição não negligenciável do Serviço Nacional de Aprendizagem Comercial (SENAC) e do Serviço Nacional de Aprendizagem Industrial (SENAI), instituições mistas criadas pelo Governo, mas mantidas, a primeira, pelo Comércio e a segunda pela Indústria, ambas com escolas profissionais de nível pós-primário em todo o território nacional. Criadas na década de 1940, elas têm fornecido o maior contingente de mão-de-obra qualificada para o comércio e a indústria e a eficácia de sua atuação nesse sentido é indiscutível, já que, controladas e mantidas pelos setores interessados, estão, desde sua criação, empenhadas em treinar realmente o pessoal para os setores respectivos.
\end{abstract}

Portanto, as camadas populares passaram a procurar mais as escolas profissionalizantes, pois ofereciam cursos de formação, preparavam rapidamente para o mercado de trabalho, afinal tratava-se de uma população de jovens que tinham urgência em se qualificar, além dos trabalhadores que já estavam empregados e que necessitavam de um aperfeiçoamento profissional para a melhoria de sua remuneração.

Além do mais, a nova fase de expansão da indústria necessitava de uma formação mínima dessa classe trabalhadora. Neste sentido, a criação do Serviço Nacional de Aprendizagem Industrial (SENAl) e Serviço Nacional de Aprendizagem Comercial (SENAC), chamadas de instituições mistas, criadas pelo governo e mantidas pelo comércio e pela indústria, passou a 
fornecer maior contingente de mão de obra. Ainda nesse sentido, o governo regulamentou dois Decretos-lei de $n^{\circ} 4.481$, de 16 de julho de 1942, nos quais todo estabelecimento ou indústria deveria empregar $8 \%$ de aprendizes e menores correspondentes ao número de funcionários. Era exigido também que estivessem devidamente matriculados nas escolas do SENAI, tendo como prioridade os filhos dos "menos favorecidos".

Ressalte-se que a ideia de atendimento dos "menos favorecidos" escamoteia as razões materiais que geram a massa de trabalhadores em condições de pobreza. Trata-se, evidentemente, de uma resposta do capital para as lutas históricas dos trabalhadores por melhores condições de trabalho.

É importante enfatizar que a criação do SENAI e do SENAC teve como parâmetro a Reforma Capanema, que orientou as propostas pedagógicas do Ensino Profissional. De acordo com Silva (2009), a criação do SENAl teve forte influência norte-americana nas suas bases metodológicas, sendo essas constituídas pelos paradigmas do Taylorismo e do Fordismo, ambos com vertentes racionalistas-produtivistas. Diante do exposto, é importante caracterizá-las para compreender suas convergências.

O taylorismo, idealizado por Frederick Winslow Taylor, racionalizou os movimentos com utilização de instrumentos adaptados às tarefas, sobre o qual havia o controle do trabalhador para que o mesmo fosse mais produtivo. Já o fordismo, idealizado por Henry Ford, nada mais foi do que o aperfeiçoamento do Taylorismo, ou seja, um método aplicado nas grandes indústrias automobilísticas, que se fundamentava na linha de montagem acoplada às esteiras rolantes evitando o deslocamento do operário.

Segundo Gomes (2013, p.70):

Ressaltadas as diferenças, convém lembrar que ambos os métodos tratam de estratégias de gestão que objetivavam o aumento da produtividade na organização e na racionalização do trabalhador. Também enfatizavam a separação entre concepção e execução de tarefas, além de, para compensar seus trabalhadores pela estafa causada na rotina das atividades, oferecer algumas recompensas salariais. 
Foram justamente baseados nos modelos da organização científica do trabalho que o SENAI e SENAC, inicialmente, formularam suas propostas pedagógicas para a qualificação. Segundo Manfredi (1998), tais escolas se fundamentaram no modelo job/skills definidos a partir da posição a ser ocupada no processo de trabalho e previamente estabelecido nas normas organizacionais da empresa (p.3). Igualmente, a Reforma Capanema possuía pedagogias de cunho restritamente tecnicista (grifo do autor).

Neste contexto, fica claro que o trabalhador tinha uma educação com separação definida entre concepção e execução. A maioria dos trabalhadores era "treinada" para determinadas funções e a qualificação oferecida era aligeirada.

Diante disso, o modelo de educação profissional no Brasil acaba por caracterizar-se pela incipiência do conhecimento do sistema produtivo como um todo, coerente com o propósito de reprodução da ordem mantida pelo capital. Em síntese, o modelo de Educação Profissional no Brasil da década de 40, baseado nos moldes taylorismo e no fordismo, reafirmouse nas décadas seguintes.

Com o fim da ditadura do Estado Novo em 1945, verificou-se o advento de eventos democráticos. No entanto, o retorno da democracia deve ser visto com ressalvas. A legislação trabalhista continuou a mesma do Estado Novo; o sistema eleitoral continuava impedindo a participação dos analfabetos, que constituíam uma grande parcela do eleitorado; também é importante salientar que o Partido Comunista Brasileiro foi cassado, bem como seus representantes parlamentares em 1947.

No âmbito das políticas econômicas, apresentavam-se dois projetos distintos: de um lado, um segmento da burguesia que advogava a abertura ao capital estrangeiro; de outro, um segmento dos grupos dominantes que defendiam a constituição de um capitalismo nacional com a reserva dos setores estratégicos da economia nas mãos do Estado ou da chamada burguesia nacional. 
No entanto, é importante ressaltar o fortalecimento do movimento operário, assim como o crescimento dos sindicatos, o que acaba causando desconforto nos setores conservadores, conforme apontamentos de Gomes:

\begin{abstract}
Em contrapartida, cabe ressaltar o renascimento do movimento operário como elemento importante para a conjuntura política do período. Ao mesmo tempo em que o ano de 1945 foi pontilhado por movimentos reivindicatórios, crescia a taxa de sindicalização entre os trabalhadores e ampliava-se a atividade política nos sindicatos, 0 que assustava os setores conservadores (GOMES, 2001, p.57).
\end{abstract}

O retorno de Vargas em 1950 significou provisoriamente a vitória dos segmentos que defendiam a possibilidade de construção de um modelo capitalista autônomo e nacional. Ao mesmo tempo, Vargas também era visto como uma força capaz de controlar os trabalhadores em suas reivindicações, "a corrente nacionalista teve de lutar incrivelmente contra as tendências da ala política que preconizava maior compromisso com o capital internacional" (ROMANELLI, 1978, p.52).

O acirramento das disputas no início da década de 1950 empurrou a direção do Estado para uma opção política de abertura ao capital estrangeiro, visto como essencial para o desenvolvimento da "nação". Esse projeto ficou cada vez mais cristalino com a ascensão de Juscelino Kubitschek.

O acelerado crescimento econômico do período demandava mão de obra, o que evidentemente contribuiu para acirrar os debates em torno das questões educacionais. Nesse cenário, acentuaram-se as contradições do desenvolvimento brasileiro. Ao mesmo tempo em que o país crescia a taxas significativas, crescia a miséria entre os trabalhadores. O crescimento industrial e a mecanização do campo ampliavam o crescimento das cidades e o movimento dos trabalhadores por melhores condições de trabalho. O resultado materializou-se no endividamento externo, nos índices inflacionários e na instabilidade política. Não por acaso, o período também 
é marcado pelas disputas entre conservadores e liberais, em torno do projeto da LDB que viria a ser promulgada somente em 1961.

Após a renúncia de Jânio Quadros e a tentativa de golpe orquestrada pelos setores mais conservadores contra a posse de João Goulart, verificouse a solução de compromissos com a adoção do Parlamentarismo em 1961. Ressalte-se que os velhos interesses ligados aos grandes latifundiários e a burguesia brasileira, associada ao capital estrangeiro, foram determinantes para o desfecho da crise da renúncia de Jânio Quadros.

Naquele cenário conservador foi promulgada a LDB 4.024/61, que traduzia também um compromisso entre liberais e conservadores, estes identificados com a defesa dos interesses privados em educação. Tratava-se de nossa primeira Lei de Diretrizes da Educação. Observa-se que as proposições proclamadas em seus artigos são genéricas e pouco objetivas:

Art. $1^{\circ}$ - A educação nacional, inspirada nos princípios de liberdade e nos idéias de solidariedade humana, tem por fim: a) A compreensão dos direitos e deveres da pessoa humana, do cidadão, do Estado, da família e dos demais grupos que compõem a comunidade; b) $O$ respeito à dignidade e as liberdades fundamentais do homem;c) $O$ fortalecimento da unidade nacional e da solidariedade internacional; d) 0 desenvolvimento integral da personalidade humana e a participação na obra do bem comum; e) O preparo do individuo e da sociedade para o domínio dos recursos científicos e tecnológicos que the permitam utilizar as possibilidades e vencer as dificuldades do meio; f) A preservação e expansão do patrimônio cultural; g) A condenação a qualquer tratamento desigual por motivo de convicção filosófica, política ou religiosa, bem como a quaisquer preconceitos de classe e raça (ROMANELLI, 1978, p. 180).

O que ficou claro foi que a Lei 4.024/61, Lei de Diretrizes e Bases (LDB), não trouxe mudanças significativas. Segundo Romanelli (1978), a vantagem da legislação deveu-se ao fato de não ter prescrito um currículo fixo para o território nacional, o que impediu a rigidez, além de permitir a descentralização nas questões educacionais, sendo instituído na sequência o Conselho Federal de Educação e os Conselhos Estaduais de Educação. Foram criados também o Plano Nacional de Educação (1962) e o Programa 
Nacional de Alfabetização, inspirados no método Paulo Freire, com a coordenação do Ministério da Educação (MEC).

No entanto, o clima de acirramento das disputas ideológicas da Guerra Fria, o exemplo da Revolução Cubana e o crescimento das manifestações de trabalhadores do campo e da cidade levaram a burguesia, associada ao capital estrangeiro a diagnosticar a situação como temerosa para seus interesses.

Nesse cenário, não faltaram clamores para a intervenção militar contra a "ameaça comunista". As tentativas de superação da crise, como o Plano Trienal3, caíram por terra, diante das contradições presentes no capitalismo. Dessa forma, com o apoio das forças imperialistas americanas e com adesão das Forças Armadas, o desfecho da crise materializou-se no Golpe de Estado de 1964. Em outras palavras, o golpe foi a arma da burguesia contra o avanço da luta dos trabalhadores. De acordo com Saviani (2011), a ditadura foi um golpe nas aspirações populares que implicavam em luta pela transformação da estrutura socioeconômica do país.

No âmbito da educação, durante a ditadura civil e militar, verificou-se a expansão dentro da lógica de atendimento às demandas do mercado. Não é coincidência a penetração da teoria do "Capital Humano" com o propósito de formação de mão de obra adequada às necessidades de expansão do capitalismo em nosso país.

A respeito da teoria do "Capital Humano", faz-se necessário enfatizar que cumpria a função de mascarar as diferenças entre classes e nações. O subdesenvolvimento é apresentado como fruto da ausência de investimento em educação e não ao imperialismo econômico. Por outro lado, a qualificação da mão de obra era apresentada como um requisito para alcançar o desenvolvimento e harmonia social. Cumpre salientar que a qualificação da mão de obra significava adequar a educação escolar aos

\footnotetext{
3 Proposto pelo Ministro do Planejamento Celso Furtado no governo de João Goulart, o Plano TRIENAL era uma resposta política para a disparada da inflação, que se encontrava em 1963 na taxa de 78,4\%1, e a deterioração do comércio externo.
} 
ditames do mercado. Portanto, tratava-se de uma tarefa técnica, não política.

Nesse sentido, os educadores tornaram-se meros executores dos programas educacionais.

[...] O processo pedagógico fica cada vez mais entregue aos especialistas que "pensam", programam e supervisionam a decodificação da programação pré-estabelecida. A divisão interna do trabalho escolar (o surgimento dos chamados "especialistas em educação"), posta como mecanismo de racionalização e maior eficiência do sistema de ensino, dentro das condições concretas da divisão social do trabalho, acaba se constituindo numa medida de esvaziamento e desqualificação do processo pedagógico (FRIGOTTO, 2010, p.191).

Dentro dessa lógica, verifica-se o advento da Lei $n^{\circ} 5.692 / 71$, que altera a LDB 4.024/1961, que amplia os anos de estudo para o primeiro e segundo graus ( 11 anos), sendo o ensino profissionalizante integrado uma tentativa de incremento da produtividade econômica da sociedade. Por meio da legislação, objetivava-se a unificação vertical do antigo ensino primário e médio, eliminando-se a diferença entre ramos, tais como secundário, agrícola, industrial, comercial e normal, e articulando-se as diferentes ações curriculares no interior de cada série e ao longo das séries desde o início do primário até o final do segundo grau (SAVIANI, 2011).

Segundo Silva (2009), a Lei $n^{\circ} 5.692 / 71$ instituiu para $\circ 2^{\circ}$ grau a obrigatoriedade da qualificação profissional. A intenção era profissionalizar o maior número de pessoas possível, substituindo os antigos ramos propedêuticos e profissionalizantes do ensino médio por um sistema único reafirmado pelo mesmo:

Como a maioria que chegava ao ensino médio era barrada neste nível e não para o ensino superior, enfim, a educação continuava excludente. As escolas particulares, por sua vez, reforçavam o ensino propedêutico, direcionando o aluno para - vestibular. O intuito de aliar a educação básica à profissionalizante da Lei n. 5.692 revela a preocupação primeiro de atender às demandas de trabalho, transparecendo a ideologia da racionalidade técnica que subordina a 
educação de caráter universal aos interesses técnicos da sociedade liberal (GOMES, 2013, p.73).

Percebe-se que a Lei 5.692/71 objetivava promover a profissionalização compulsória, com vistas a reduzir a demanda de candidatos ao ensino superior ao mesmo tempo em que buscava promover o nível geral de escolarização para o atendimento das necessidades da expansão industrial, em bases subordinadas ao imperialismo. No entanto, a profissionalização compulsória agravou a desqualificação do trabalho escolar. A forma pela qual foi introduzida a profissionalização não gerou o efeito desejado.

Desse modo, a proposta de ensino profissionalizante fracassou por vários motivos, entre os quais a falta de estrutura das instituições de ensino mantidas pelo Estado, o que reforçava as diferenças entre as escolas que atendiam preferencialmente os filhos da burguesia e as escolas precárias dos filhos da classe trabalhadora. Devido a vários problemas, a Lei 5.692/71 foi revogada pela Lei 7.044/1982, que não excluiu o ensino profissionalizante, no entanto, ele perde o caráter universal e compulsório.

Nesse viés, Saviani afirma:

[...] a profissionalização universal e compulsória do ensino de segundo grau enfrentou vários percalços, acabando por ser revogada pela Lei n. 7.044 de 18 de outubro de 1982. A partir daí, conquanto a profissionalização não tenha sido excluída, ela perdeu o caráter universal e compulsório de que revestia na Lei $n^{\circ} .5 .692 / 71$. As medidas decorrentes das Leis $n^{\circ}$. 5.540/68 e $n^{\circ} .5 .692 / 71$ integram um conjunto de iniciativas tomadas no âmbito do regime autoritário caracterizado pelo fechamento político (SAVIANI, 2011, p.38).

Fica claro que as políticas públicas para a educação implementadas no contexto político de 1964 refletia o viés autoritário e centralizador da ditadura no Brasil. Aos educadores cabia a tarefa de executores das diretrizes emanadas pelo Estado.

Em 1985, com o fim da Ditadura Civil-Militar, verifica-se um novo cenário para os debates no campo da educação. No entanto, o fim do 
ciclo militar não significou o término da hegemonia burguesa, pelo contrário. Verifica-se que a defesa da democratização por parte do capital veio acompanhada do discurso de redução do Estado, apresentado como autoritário pelos intelectuais da ordem burguesa.

Com a promulgação da Constituição de 1988, a eleição presidencial de 1989 e a ascensão de Fernando Collor de Melo, percebe-se o fortalecimento do discurso neoliberal apresentado como única alternativa viável diante do processo de restauração do capitalismo na U.R.S.S e das demais nações do Leste europeu. Trava-se uma nova etapa expansionista da internacionalização da economia que contribuiu para a ampliação das desigualdades sociais.

Naquele cenário, marcado pela euforia dos intelectuais comprometidos com a defesa da ordem capitalista, foi convocada a Conferência de Educação para todos, em Jomitien, Tailândia, pela Organização das Nações Unidas para a Educação, a Ciência e a Cultura (UNESCO), o Fundo das Nações Unidas para a Infância (UNICEF), o Programa das Nações Unidas para o Desenvolvimento (PNUD) e o Banco Mundial. Tratava-se de explicar as diferenças entre as nações como resultado da ausência de educação. Em outras palavras, era empurrado para debaixo do tapete da história as verdadeiras causas das diferenças entre as nações.

Na Conferência foram estabelecidas metas a serem alcançadas pelas nações que apresentavam "baixa produtividade do sistema educacional" que serviu como ponto de partida para a elaboração do Plano Decenal de Educação Para Todos (1993), que concebia a erradicação do analfabetismo no Brasil e ações para universalização do ensino fundamental nos estados e nos municípios. Diante das transformações econômicas, mais uma vez a educação passava a ser apontada como um requisito básico para formação de trabalhadores e desenvolvimento econômico, o que justificaria a necessidade de um novo modelo de formação que acompanhasse as mudanças tecnológicas. 
Nesse cenário da hegemonia neoliberal e das proposições de um "Estado mínimo", o governo Fernando Henrique (1995-2002) promoveu uma série de reformas, incluisive no campo educacional, que objetivava reforçar o domínio do capital sobre o trabalho.

Há muitos anos, existe na literatura educacional brasileira uma
discussão sobre a verdadeira identidade do ensino médio. Na
maioria dos casos, questionava-se qual seria o verdadeiro
papel dessa etapa do ensino: preparar para a continuidade
dos estudos nas universidades ou uma formação profissional.
De uma forma pouco democrática, ancorada no discurso de
uma economia globalizada e na necessidade do
desenvolvimento de novas competências nos educandos,
durante a gestão do Presidente Fernando Henrique Cardoso, o
governo brasileiro implementou uma modificação radical no
interior do ensino, separando a formação profissional do ensino
médio. Aparentemente, tal separação viria ao encontro das
aspirações dos educadores que criticavam a fragmentação no
interior secundário. No entanto a realidade não foi bem assim.
O que de fato houve foi a privatização da educação e sua
redução ao desenvolvimento de habilidades específicas para
o mercado de trabalho (OLIVEIRA. In: BATISTA; MEIRE, 2013 , p.
219).

$\mathrm{Na}$ verdade, as reformas empreendidas no período só devem ser compreendidas como um desdobramento das estratégias levadas adiante pelo Banco Mundial e o Banco Interamericano de Desenvolvimento, que financiaram $\bigcirc$ Programa de Expansão da Educação Profissionalizante (PROEP). Conforme o Decreto $n^{\circ} 2.208$, de 17 de abril de 1997; Portaria do MEC $n^{\circ}$ 646, de 14 de maio de 1997; Lei Federal n 9.649, de 27 de maio de 1998. Nesses documentos se estabelece que o ensino médio se desvincule totalmente da educação profissional, além de alterar a organização dos cursos que passam a ser estruturados em disciplinas agrupadas, acelerando a qualificação de profissionais para o mercado de trabalho, portanto, uma organização política pedagógica de curso de curta duração.

De acordo com Ortigara apud Batista; Meire (2013), com a Portaria MEC 646/1997, O governo FHC limitou a oferta de ensino médio nas instituições federais, de modo que as escolas não poderiam oferecer mais de $50 \%$ das vagas para tal modalidade, portanto, as novas instituições deveriam 
ofertar somente o ensino profissionalizante. Nessa perspectiva, nota-se que o governo FHC optou por uma educação técnica centrada na produtividade da política de baixo custo.

Com a eleição de Luís Inácio Lula da Silva e sua posse em 2003, ainda que se identifiquem algumas diferenças no âmbito das políticas públicas educacionais, não se pode negar muitas continuidades. Tratou-se, em última instância, de um projeto de conciliação de classes e a aposta do acúmulo de forças dentro dos espaços permitidos pelo capital. Na prática, os projetos para educação, e mais especificamente para educação profissional, eram adequados à ordem burguesa.

Sobre a educação profissional, cabe enfatizar que $\circ$ Decreto $n^{\circ}$ 5.154/2004, revogou o Decreto no 2.208/1997. Para Ortigara, apud Batista; Meire (2013), em 2008, as diretrizes previstas no Decreto $n^{\circ} 5.154 / 2004$ foram submetidas ao processo legislativo, sendo aprovadas, praticamente, na íntegra e incorporadas na LDB por meio da Lei no 11.174/2008.

De acordo com essa nova legislação, estabelecem-se três possibilidades entre a educação técnica profissional e ensino médio: integrada, concomitante e subsequente.

\footnotetext{
É importante assinalar que a possibilidade de integração do ensino médio com o ensino técnico representou um avanço no processo de redução da dualidade entre essas modalidades de educação. No entanto, o Decreto n 5.154/2004 manteve as possibilidades de segmentação, como a organização do currículo em módulos com saídas intermediárias, que possibilitam a obtenção de certificado de qualificação para o trabalho, sendo uma característica da educação profissional voltada aos interesses da forma capitalista da produção (ORTIGARA. In: BATISTA; MEIRE, 2013, p.269).
}

Ainda no governo Lula, em 2006 ocorreu a Conferência Nacional de Educação Profissional e Tecnológica com a participação de grupos que atuavam no setor. Na pauta do debate foram discutidas a descentralização, a expansão geográfica e a interiorização da Educação Profissional e Tecnológica (EPT), assim como as ampliações de vagas. 
Após cinco meses da Conferência Nacional de Educação Profissional e Tecnológica, o governo lançou o Plano de Desenvolvimento de Educação (PDE), que propôs a reorganização das instituições da Rede Federal para a Educação Federal:

\begin{abstract}
Considerando que a reorganização administrativa era inevitável, em razão da expansão da Rede Federal, condição proporcionada pela organização multicampi dos Institutos. Na Rede Federal, com a criação dos Institutos como mecanismos de implementação de políticas para a educação profissional, o Governo Lula indicou a direção da integração entre o ensino propedêutico e o ensino profissional. Aproveitou-se, pois, das medidas de reorganização da expansão para orientar as instituições no sentido de organizarem seus projetos pedagógicos segundo uma concepção de educação que possibilitou o rompimento do ciclo vicioso e da reprodução histórica dos grupos dominantes. Orientou-se enfim, para a elaboração de projetos pedagógicos que buscassem a redução da dualidade entre a formação propedêutica e a formação profissional (ORTIGARA. In: BATISTA; MEIRE, 2013, p. 277).
\end{abstract}

Portanto, fica claro que uma das finalidades dos institutos foi de alguma forma tentar promover a integração da educação básica e técnica, no entanto é necessário superar os interesses da classe burguesa, para promover uma política educacional que avance no sentido de combater a dualidade educacional de fato. Em outras palavras, suplantar a dualidade estrutural histórica entre o ensino médio propedêutico e a educação profissional de nível médio requer a superação de desafios para transformar essa realidade. Para isso, trata-se de democratizar o acesso ao ensino com o provimento de condições adequadas para o funcionamento da escola que descaracterize o assistencialismo e a filantropia presentes no ideário liberal.

\title{
CONSIDERAÇÕES FINAIS
}

As contradições percebidas no movimento histórico do ensino profissionalizante caracterizam-se por meio de encontros e desencontros entre a Educação Profissional, a Educação Básica e Educação Superior. 
Dessa forma, verifica-se ao longo da história da educação brasileira, e mais especificamente no período republicano, um ensino profissionalizante inserido em um modelo dual que demarca a trajetória educacional para burguesia e para os filhos dos trabalhadores.

O papel desempenhado pela escola ao longo da República Velha pode ser sintetizado na preparação dos filhos das classes dominantes para o preenchimento de quadros para a política e administração pública. No entanto, as contradições no interior dos grupos dominantes e o processo de urbanização com a nascente indústria gerou a demanda social por educação.

As reformas empreendidas não alteraram de forma significativa as condições materiais de funcionamento das escolas ou de acesso aos filhos da classe trabalhadora. Nem mesmo a chamada "Revolução de 1930" rompeu com a dualidade estrutural. Os cursos profissionalizantes não eram destinados aos filhos da burguesia, mas aos que não possuíam condições materiais de prosseguir seus estudos, seja no nível secundário, seja no universitário.

A ditadura civil-militar de 1964-85 manteve a tendência dualista no âmbito educacional. Apesar das pressões populares pela ampliação de vagas na educação básica e superior, a "solução" pela formação técnica, com a Reforma da educação básica promovida pela Lei n $n^{\circ} 5.692 / 71$, não garantiu a plena inserção do jovem no mercado de trabalho. A compulsoriedade se limitou ao âmbito das escolas públicas, sem condições físicas e pedagógicas para o atendimento da lei. Por sua vez, as escolas privadas permaneceram com os currículos propedêuticos orientados para as ciências, letras e artes, atendendo aos filhos das classes média e burguesa.

A LDB n 9.394, de 1996, não foi capaz de romper com o quadro de dualidade descrito, afinal, segundo Kuenzer (2007, p.34):

a dualidade estrutural tem suas raízes na forma de organização da sociedade, que expressa as relações entre capital e trabalho; pretender resolvê-la na escola, através de uma nova concepção, ou é ingenuidade ou é má-fé. 
Dessa forma, o propósito dos cursos profissionalizantes, em diferentes momentos, adquiriu caráter de terminalidade e apontava para a incapacidade do sistema em democratizar o acesso à educação superior.

Atualmente, mais do que nunca, o campo da educação tornou-se estratégico para os interesses do capital. Em sentido amplo e geral, o discurso hegemônico aponta para a necessidade de formação da educação para a solução dos problemas referentes à força de trabalho.

Diante do que foi discutido ao longo do trabalho, compreende-se que não se atenderá às demandas dos filhos da classe trabalhadora, apenas com decretos ou reformulação de leis para propiciar a formação profissional. É imperativo transformar a realidade material da sociedade dividida, na qual a rede de ensino promove a inclusão dos filhos da classe trabalhadora de forma precarizada e que não garante oportunidades de empregos para todos, pois simplesmente essa proposição é utópica em uma sociedade capitalista.

Por isso, é fundamental resgatar a centralidade do homem no cumprimento das finalidades da educação básica, pois o objetivo não deve ser a formação de técnicos para adequação ao mercado, mas de pessoas que compreendam a realidade, que possam também atuar de forma a transformá-la.

\section{REFERÊNCIAS}

BRASIL.. Decreto $n^{\circ}$ 7.566, de 23 de setembro de 1909. Cria nas capitais dos Estados da República Escolas de Aprendizes Artífices, para o ensino profissional primário e gratuito. Rio de Janeiro, 1909. Disponível em:<http://portal.mec.gov.br/setec/arquivos/pdf3/decreto_7566_1909.pdf>. Acesso em 28 de jun. de 2014.

CARVALHO, J. G. M. de. História, trabalho e educação: a educação profissional no Brasil. 2008. 64f. Dissertação (Mestrado de Educação) Faculdade de Educação, Universidade Estadual de Campinas, 2008. Disponível em: <http://www.bibliotecadigital.unicamp.br/document/? code = vtls000436593>. Acesso em: 09 de jul. de 2015. 
FRIGOTTO, G. A produtividade da escola improdutiva: um (re) exame das relações entre educação e estrutura econômica-social capitalista. São Paulo: Cortez, 2010.

GALLINDO, J. Formação para o trabalho e profissionalização no Brasil: da assistência à educação formal. In: BATISTA, E. L.; MEIRE, T. M. A educação profissional no Brasil: história, desafios e perspectivas para o Século XXI. Campinas, SP: Alínea, 2013.

GOMES, M. A. O. O PT e a educação: a participação dos intelectuais católicos na gestão Luiza Erundina (1989-1992). III Seminário de Teses e Dissertações em Andamento - Reforma Universitária, 2004, Campinas: Gráfica FE / Unicamp, 2001.

GOMES, H. S. C. Os modos de organização e produção do trabalho e a Educação Profissional no Brasil: Uma história de dualidade e racionalidade técnica. In: BATISTA, E. L.; MEIRE, T. M. A educação profissional no Brasil: história, desafios e perspectivas para o século XXI. Campinas: Alínea, 2013.

KUENZER, A. (org.). Ensino médio: construindo uma proposta para os que vivem do trabalho. 5. ed. S. Paulo: Cortez, 2007.

OLIVEIRA, R. A reforma da educação Brasileira nos anos 90. In: BATISTA, E. L.; MEIRE, T. M. A educação profissional no Brasil: história, desafios e perspectivas para o Século XXI. Campinas, SP: Alínea, 2013.

ORTIGARA, C. P. G. Os Institutos Federais de educação, ciência e tecnologia: permanência e mudanças. In: BATISTA, E. L.; MEIRE, T. M. A educação profissional no Brasil: história, desafios e perspectivas para o Século XXI. Campinas, SP: Alínea, 2013.

RODRIGUES, J. Celso Suckow da Fonseca e a sua "História do ensino industrial no Brasil". Revista Brasileira de História da Educação, Campinas: Autores Associados, n.4 jul/dez 2002. Disponível em:

<http://www.rbhe.sbhe.org.br/index. php/rbhe/article/view/246>. Acesso em: 03 de fev. de 2015.

ROMANELLI, O. de O. História da Educação no Brasil. 14. ed. Petrópolis: Vozes, 1978.

SAVIANI, D. Pedagogia Histórico-Crítica: primeiras aproximações. Campinas: Autores Associados, 2011.

SILVA, L. M. de O; MATTOS, F. A. M. de. Welfare State e emprego em saúde nos países avançados desde o Pós-Segunda Guerra Mundial. Revista

Economia Política, São Paulo, v.29, n.3, p.135-152, jul/set 2009. Disponível em: 
<http://www.scielo.br/scielo.php?pid=S0101-31572009000300008\&script=sci_ arttext>. Acesso em: 04 jun 2015.

THEODORO, M. (org.). As políticas públicas e a desigualdade racial no Brasil: 120 anos após a abolição. Brasília: Ipea, 2008. Disponível em:

<http://www.novamerica.org.br/medh2/arquivos/Livro_desigualdadesraciais. pdf>. Acesso em: 30 jan 2018.

Recebido em: 02.02.18

Aprovado em: 15.05.19

(c) (1) (8) 